\title{
THE USE OF EDUCATIONAL SEISMOGRAPHS IN THE SEISMOLOGY SCHOOL NETWORK "EGELADOS"
}

\author{
Fermeli G. ${ }^{1}$, Vitsas T. ${ }^{2}$, Foundas P. ${ }^{3}$, Sokos E. ${ }^{4}$, Alexandropoulou S. ${ }^{5}$, \\ Papatheodoropoulos P. ${ }^{2}$, Germenis N. ${ }^{4}$, Nikolaidis A. ${ }^{6}$ and Zevgitis T. \\ ${ }^{1}$ Department of Hist. Geology and Palaeontology, Faculty of Geology and Geoenvironment, \\ National and Kapodistrian University of Athens, Panepistimiopolis, 15784 Zographou, \\ Athens, Greece,gfermeli@geol.uoa.gr \\ ${ }^{2}$ General Lyceum of Kyparissia, 24500 Kyparissia, Greece, theoviki@vodafone.net.gr \\ ${ }^{3}$ Industrial Systems Institute, Bldg of Patras Science Park, Stadiou Str., 26504 Platani, \\ Patras,Greece,foundas@isi.gr \\ ${ }^{4}$ Faculty of Geology, Seismological Laboratory, University of Patras, 26110 Panepistimiopolis Rio, \\ Patras,Greece,esokos@upatras.gr \\ ${ }^{5}$ Buraue of Environmental Education - Messinia Prefecture, Vas. Georgiou square, OTE building, \\ 24100 Kalamata, Greece, perivallon@srv-dide.mes.sch.gr \\ ${ }^{6}$ Bouga's School, Kalamata, Greece,protypofro@yahoo.gr \\ 7 2nd Gymnasium of Messini, Messini, Greece,tzevgit@gmail.com
}

\begin{abstract}
In this paper we attempt to describe the experience we gained, working with a specially designed seismograph as an educational device. It is a modern instrument with short period response, GPS timing and digital recording on personal computer. The installation was done in the frame of the local seismology school network, called "Egelados".

The knowledge of basic concepts of geology, physics and mathematics (Lower High School level Gymnasium) is a prerequisite for the use of the instrument. Further research of the earthquake phenomenon and the analysis of the recorded data leads to didactic objectives in sciences and mathematics which are included in the Lyceum curriculum. The reliability test of the results obtained using the seismograph has, from the analysis students made, shown up to now declinations of the events magnitude of 0,2 - 0,4 when compared to magnitudes published by National Observatory of Athens-Institute of Geodynamics. Students' constructions to overcome the calculation difficulties to find the exact location of epicentre are often proposed activating in this way their research mood.

Up to now the use of the tool, in the framework of network "Egelados", not only connects the participating schools but also gives the opportunity for further collaboration among teachers and students that have installed a similar instrument. Finally, everyday use of the seismograph reveals its drawbacks and provides ideas of enhancements.
\end{abstract}

Key words: sciences education, earthquakes, educational seismograph, environmental education, Egelados network. 


\section{Introduction}

\subsection{The International experience}

At an international level, during the last three decades educational institutes suggest and attempt the introduction, to the school's curriculum, of programs - activities related to geosciences. Such projects are currently, at least in United Stated of America (USA), connected under the umbrella of larger collaborations between institutions such as the U.S. Educational Seismology Network (USESN 2001). The goal of USESN is to provide a mechanism for coordination of individual efforts, to provide common technical and educational resources that will enhance all of the educational seismology programs, and provide a mechanism for advocacy for educational seismology (USESN 2001). The Princeton Earth Physics Project (PEPP http://www.indiana.edu/ pepp/) is a network of seismic recording stations in high schools across the United States for educational purposes. Students use the PEPP network to study earthquakes and develop scientific and mathematical skills in the classroom using real seismic data. PEPP's aim is to engage students in the process of hands-on science and inquiry-based learning by operating their own seismological observatory and gathering and analyzing research quality data.

EDUcational SEIsmological (EDUSEIS) project in Europe makes also an attempt to connect schools with science museums and research institutions through the earthquake phenomenon (EDUSEIS http://www.eduseis net/; Virieux 1999; Bobbio and Zollo 2000). For the time being few schools in Europe are directly connected with EDUSEIS. Liceo Scientifico "Nicolo Copernico" of Naples, Odivelas Secondary School in Portugal and Copernicus Gymnasium Philippsburg in Germany are such schools that have also acquired seismographs. But there are also other European schools and other European projects that are running their own projects using seismographs of different construction. Such schools are "Monschau School", "Faust Gymnasium" "Staufen and St. Michael Gymnasium" in Germany, while the Projet "Sismo des Écoles" in France (Berenguer \& Virieux 2006) and the "SeisSchool" Norway project (Federenko et al. 2000; Husebye et al. 2003) are projects aiming to create interest in geosciences and seismology among high school students using seismographs.

\subsection{The Hellenic School Educational Seismology Network “Egelados"}

The thematic network Egelados was established in 2004, on a volunteer basis, as a collaboration between educators (geologists), researchers (seismologists) and engineers from schools, universities, research institutions and the Bureau of Environmental Education in Messinia prefecture.

The aim of the network is to improve scientific literacy, spark student interest in scientific research, increase their understanding of natural hazards, and to actively engage them in real-world scientific research. In order to achieve this aim the network promoted at secondary school level the use of "educational seismographs" and processing of recorded seismic data. The objectives of the network are to give to the students the basic information about the earthquake generation and the ways this phenomenon affects our life. To make students understand that earthquakes are natural phenomena, connected with the landscape formation; are frequent in Greece and thus essential for us to understand and face by constructing appropriate houses and acting in a certain way when an earthquake occurs (Fermeli et al. 2006).

Each school from the network was working at the first two years on its own project concerning the study of either volcanic or seismic activity in Greece. During those two years students attended lectures from scientists from universities and research institutions about natural disasters, volcanic activity and especially about seismic phenomena. They have also attended lectures about First Aid and participated in Earthquake related activities in their schools. Students also visited areas of great earthquake hazard and volcanoes like Santorini, Corinth (Sousaki), Naples (Vesuvius) and Sicily (Etna). 


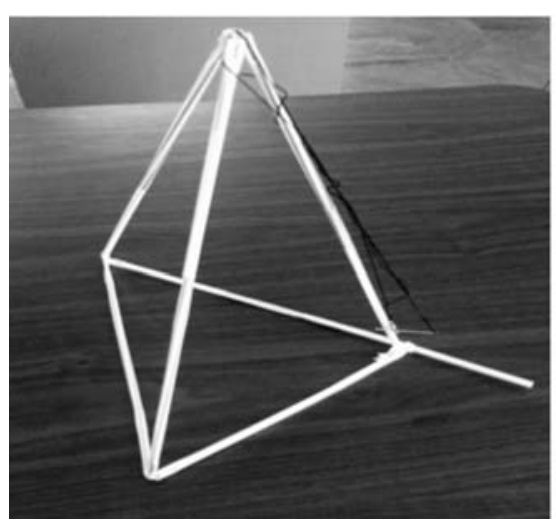

(a)

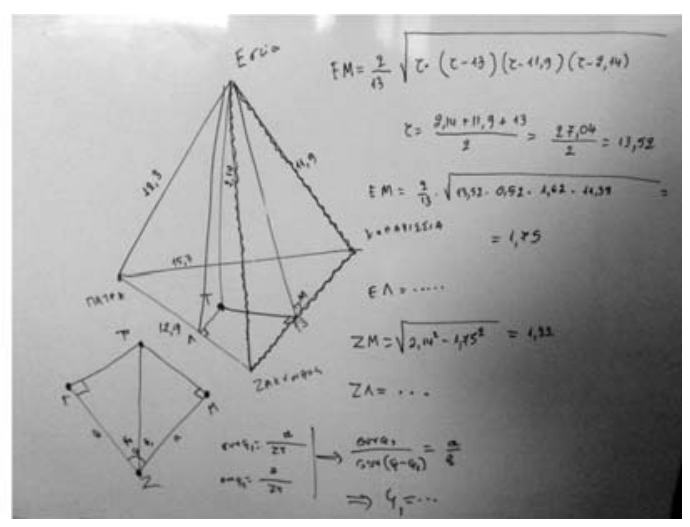

(b)

Fig. 1: Example of educational activity (a): Construction made out of straws for the estimation of an earthquake's epicentre; the edges of the tetrahedron drawn from its vertex represent the distances of the loci of the earthquake from three seismographs placed in different locations. The epicentre is empirically estimated using the plumb. (b): Geometric solution of epicentre (distances from earthquake loci been known). The epicentre is placed at the trace of the height of the tetrahedron. Its position is estimated using formulas and theorems from geometry and trigonometry of A and B Grades of lyceum.

A more intense effort to bring schools in collaboration has been made during the last two years when a network between schools has started to work, spreading the information to the partners through a web page (http://www.egelados.gr).

\section{Instruments and materials in use}

Exploring web pages of universities and schools on seismic networks, we can find a variety of instruments, didactic modules and activities, proposed for a better comprehension of the earthquake phenomenon (IRIS http://www.iris.edu/hq/; EDUSEIS http://www.eduseis.net/).

So far the steering committee of Egelados network has drawn a specific curriculum for the needs of the network. The curriculum is carried out through 20 educational activities (modules), an independent project for each school, as well as by the recording of the seismic activity through the educational seismographs. The educational activities give students the opportunity to apply their knowledge from geology, physics, mathematics, geography, and other disciplines when, for example, they try to estimate parameters of an earthquake from the data recorded by a seismograph. As well as, students use a number of instruments from school sciences laboratory, in order to explore the way waves are transmitted and affect human constructions.

All these activities not only call them to apply their knowledge in order to solve problems but also ask them to find solutions in mathematics and sciences and even more to design their own devices to estimate empirically the earthquake's depth or epicenter (Fig. 1a, 1b).

The subjects of the activities have been chosen in a way that helps students proceed in the study of an earthquake. They include a variety of activities like the following:

a) Maps and scales: Students learn how to convert distances on the map to real distances and vice versa, using a map's scale. Worksheets are used for this purpose. Real seismic data taken from school's seismograph or from seismological institutes are used in the worksheets in order for students to com- 


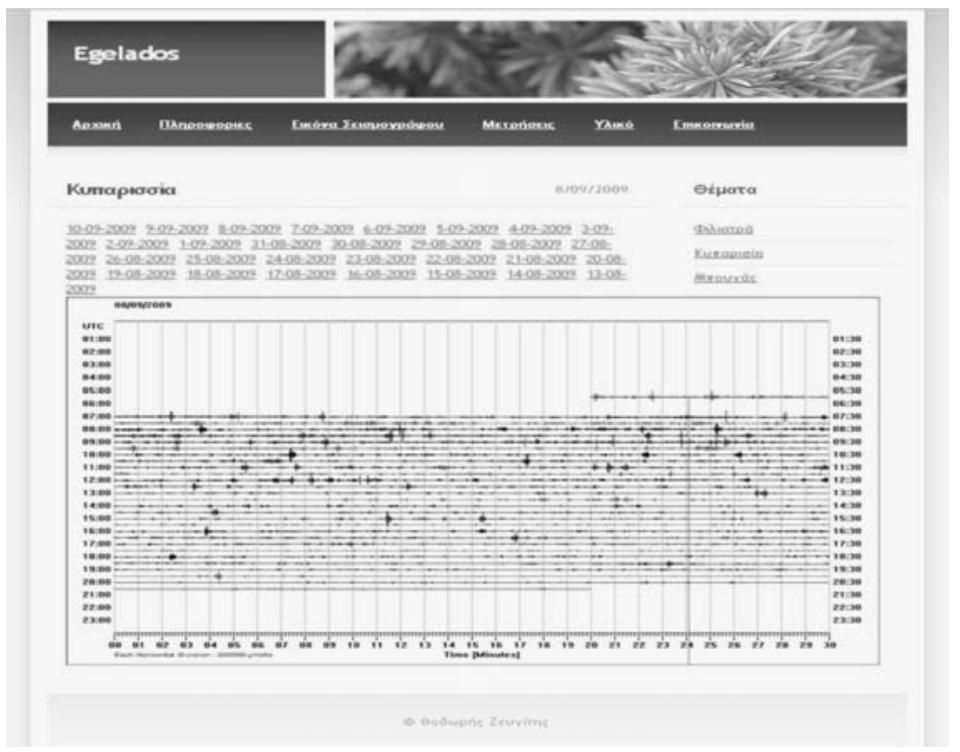

Fig. 2: Egelados' website informs the public about the aims and activities of the network. Interested visitors can see the recorded and stored data from student measurements and their works produced within the frame of the project. National and international links related to Egelados network are also presented on the site.

pare their estimations to the published results. This activity can be realized by students of A Grade $\mathrm{f}$ gymnasium up to $\mathrm{C}$ Grade of lyceum.

b) Propagation of waves: Wave types and their propagation is analyzed through presentations by teachers, experimental devices of sciences laboratory and discussion in working groups. Using worksheets students attempt to measure the distance of the loci of the earthquake from the seismograph based on, a) the different speed that transverse and longitudinal waves have, b) the subsurface structure that determines the speed of the waves and c) the distance formula for smooth linear motion. Required skills: first degree equations, laws of smooth linear motion, propagation of a wave in different materials.

c) Estimation of earthquakes loci using distances on a map under scale: Students empirically estimate the epicenter of an earthquake using the distances of the loci from three seismographs and the map scale without taking into account the depth of the loci.

d) Empirical estimation of earthquake epicentre: A more precise estimation of the epicenter (when the area estimated from the distances from the loci is large enough) is attempted through techniques that students are called to discover. Constructions like the one in figure (1a) proposed by the students not only solve the epicenters problem but also highlight their ingenuity as a result of their cooperation. Students often have to work on the surface of the map like if they live on it trying to find solutions of the epicenters problem.

e) Geometrical estimation of earthquake epicentre: Students have to use all the knowledge they have acquired in mathematics in order to solve the epicenters problem using the distances from the loci to the seismographs and the distances between the seismographs on the map. Theorems of geometry that are not yet taught to them are often necessary to be discovered so that students will give a more precise explanation on the epicenters problem.

Guesses or even conjectures and interpretations proposed by the students strengthen even more in their 
eyes the relation between mathematics, physics and geology while at the same time they realize their applications in real words problems.

Students usually work in groups, using information taken from: a)school's seismograph, b)university sites, and c)research institutions like National Observatory of Athens-Institute of Geodynamics (GI, http://www.gein.noa.gr/index-en.htm) and European Mediterranean Seismological Centre (EMSC, http://www.emsc-csem.org/index.php?page=home). Network's pedagogical activities can also be used in conjunction with the material found on the web produced by national or international organizations in Europe and USA (SSN http://www.seismosoc.org/society/education/; Eduseis http://www.eduseis.net/) which include, beyond working sheets, scientific information and real time simulations.

As well as, a webpage (http://egelados.sch.gr; Fig. 2) has established which supports schools to collaborate and spread information. Schools participating to the Egelados network have their own access code for the webpage. In this way schools can record their measurements from the school's seismograph. The measurements can help students complete their research giving them the necessary support in educational data. With the appropriate software schools can have a visual representation of the seismic activity of their region. Further development of the website could include uploading of the seismic data directly from other schools' computers so that students can have the opportunity to process and compare it with that coming from their own seismograph.

\subsection{The educational seismograph}

The most interesting tool for educational activities in the framework of Egelados network is the seismograph. This is a pedagogical tool designed specifically, by the University of Patras, Seismology Laboratory and the Industrial Systems Institute, for educational purposes (Foundas, P., and Germenis, N., 2007). The educational seismograph is a low power and low cost digital acquisition system. It was designed for monitoring of seismic events or other geophysical parameters. The device consists of two parts, a sensor and a digitizer. The sensor converts earth movement to a current (analogue signal) and is an inexpensive geophone. Both three component and one component designs are available in order to reduce the systems cost even further. The digitizer converts analogue to digital signals with a dynamic range of up to $132 \mathrm{~dB}$. It is based on a powerful, wide dynamic range delta-sigma analog-to-digital converter (ADC), with very low noise characteristics and excellent power supply rejection. The sampling rate was set to 100 samples per second. Each digitizer can support up to three analogue channels. Therefore, three ADCs can be used which operate simultaneously and independently. Each converter operates from a single power supply and utilizes fully differential inputs. The differential inputs provide common-mode rejection eliminating much of the system noise imposed on the input signal.

The digitizer also includes a complete on-board calibration circuit to correct internal offsets and gain errors or limit external system errors. Internal calibration procedures run automatically on power up. The device ensures high stability and reliable continuous operation. In order to prevent unpredictable malfunctions, a watch-dog timer function for auto self-reset on failures is also provided. Data synchronization is the process of establishing consistency among data from a source to target data storage and vice versa and the continuous harmonization of the data over time. It is fundamental to a wide variety of applications, including file synchronization and data comparison. The data synchronization is achieved using a real time clock and a phase locked loop circuit, which generates a pulse per second (PPS) signal. The first sample of data is aligned to the PPS signal. The time reference for both circuits is provided by a 12 channels GPS receiver. Connection of the digitizer to a PC is via RS232 port, which establishes a two way communication between them. Data and status information are transmitted from the digitizer to the PC and there the information is organized into packets and stored. 


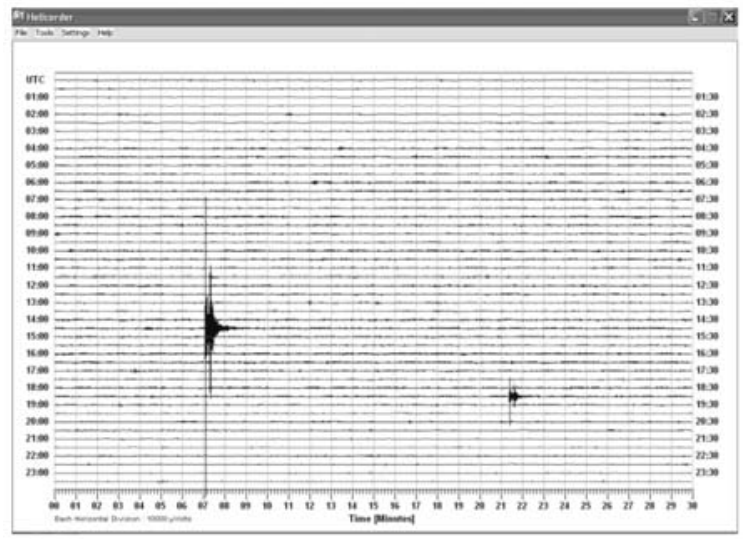

Fig. 3: Helicorder display

Various processing software is available for seismic data analysis, namely: a) DataMonitor b) DataViewer and c) Helicorder.

DataMonitor controls the serial communication and organizes the packets in data files; a new file is created every 10 minutes, absolutely synchronized to the world time.

DataViewer allows the user to work with files that were created by DataMonitor. Using the DataViewer, the user can zoom in and out in a graph, find specific features, select features that meet certain criteria, estimate the distance from the seismic event, its magnitude, and more.

The Helicorder shows 24-hour period graph of the data. The graph is «read» like a book, from left to right and top to bottom (this is the direction that time increases). As with a book, the right end of any horizontal line «connects» with the left end of the line below it (Fig. 3).

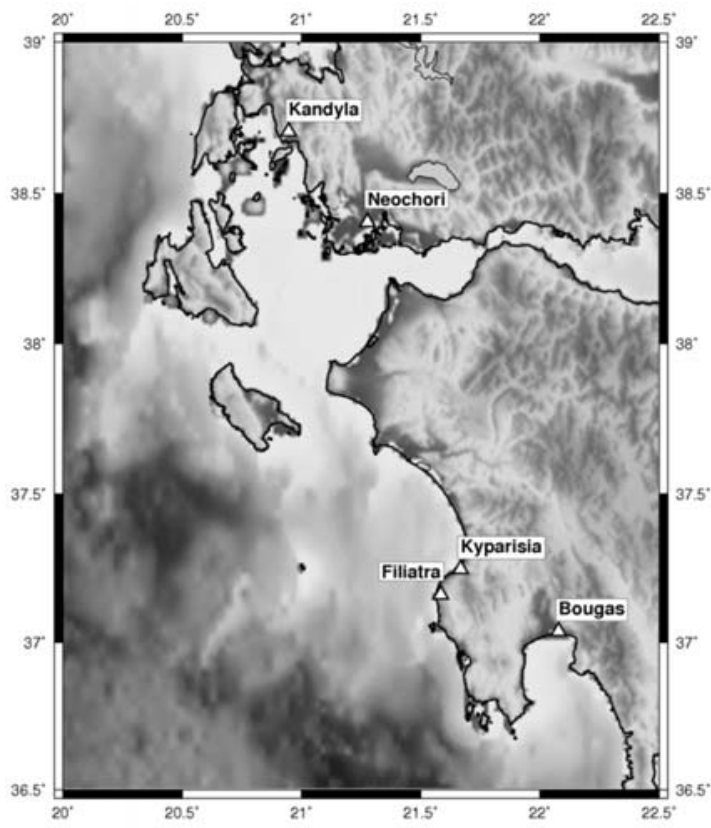

Fig. 4: Labels show network's schools in which operate educational seismographs. 


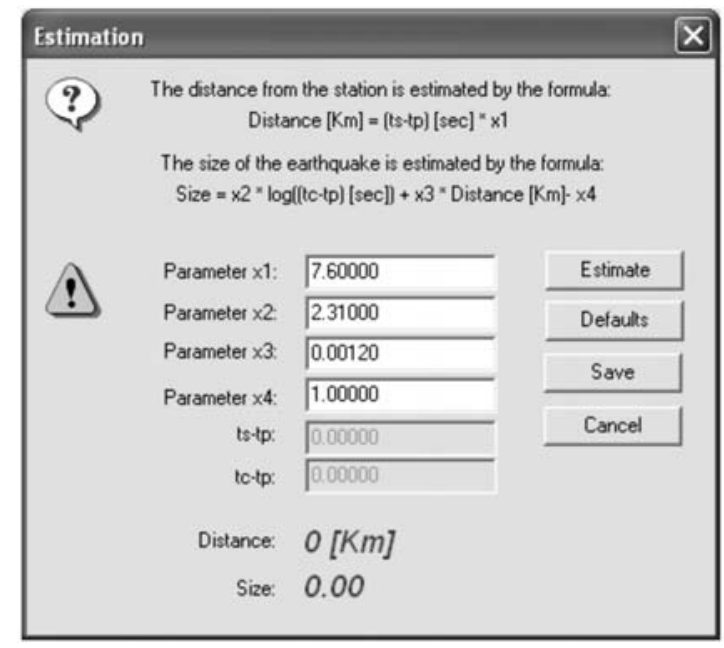

Fig. 5: Distance-magnitude estimation and parameters.

Five seismographs were installed in the first two years of this collaboration: 1) Bouga's School in Kalamata, 2) Lyceum of Filiatra 3) High School and Lyceum of Kyparissia 4) High School and Lyceum of Kandyla and 5) High School and Lyceum of Neochori (Fig. 4).

The seismographs were installed at schools under the supervision of the members of the steering committee. The network had no financial support and the seismograph's cost was provided by the schools.

\subsection{Distance-magnitude estimation and parameters}

The estimation process provided by DataViewer software gives a rough method to estimate the magnitude and the distance from the station of a seismic event (Fig. 5). The following formulas are used:

$$
\begin{gathered}
\text { Distance }[\mathrm{Km}]=\text { ts-tp }[\mathrm{sec}] * \mathrm{x} 1 \\
\text { Size }=\mathrm{x} 2 * \log (\mathrm{tc}-\mathrm{tp}[\mathrm{sec}])+\mathrm{x} 3 * \text { Distance }[\mathrm{Km}]-\mathrm{x} 4
\end{gathered}
$$

The parameters $\mathrm{x} 1, \mathrm{x} 2, \mathrm{x} 3$ and $\mathrm{x} 4$ have been provided with default values, so the user does not have to generate the information from scratch. However, teachers and students have to adjust the parameters in order to fit in to their area's geological structure by testing them and comparing their results to those of a national or an international seismological laboratory. Since precision is a necessary factor in scientific research, they have an opportunity in this way to practice in it. Of course precision is not the ultimate aim for the students working on seismic data. A seismic event should be an opportunity for them to comprehend the procedure of the generation of an earthquake creating at the same time questions in other fields of science e.g. geology, physics, mathematics.

\subsection{Instrument calibration}

Thirty three earthquakes have been used to evaluate the instrument. Most of them took place in 2009. Students estimated the magnitude of the earthquake and epicentral distance from the reference station and compared them to the data that European Mediterranean Seismological Centre or the Geodynamic Institute of Athens provides. The mean magnitude difference between school stations and EMSCs' magnitude was 0.36. The standard deviation in these differences was 0.03 to 1.09. The students observed that the difference was dependent on the distance from the station and the seis- 
Table 1.

\begin{tabular}{|c|c|c|c|c|c|}
\hline \multicolumn{6}{|c|}{ Absolute Magnitude difference versus distance } \\
\hline \multicolumn{3}{|c|}{ Bouga's School } & \multicolumn{3}{|c|}{ Kyparissia's School } \\
\hline \multirow{2}{*}{$\mathrm{N}$} & Valid & 14 & \multirow{2}{*}{$\mathrm{N}$} & Valid & 19 \\
\hline & Missing & 0 & & Missing & 0 \\
\hline \multicolumn{2}{|c|}{ Mean } & ,2579 & \multicolumn{2}{|c|}{ Mean } & ,4305 \\
\hline \multicolumn{2}{|c|}{ Median } & ,2650 & \multicolumn{2}{|c|}{ Median } & ,3900 \\
\hline \multicolumn{2}{|c|}{ Std. Deviation } & , 13268 & \multicolumn{2}{|c|}{ Std. Deviation } & ,33294 \\
\hline \multicolumn{3}{|c|}{ ( 3 channel configuration) } & \multicolumn{3}{|c|}{ ( 1 channel configuration) } \\
\hline
\end{tabular}

mograph's configuration (one or three components). In particular, the mean magnitude difference was smaller (0.24) when the earthquakes took place in areas near the stations (distance $<60 \mathrm{~km}$ ). It was also smaller if the source data have been recorded by a three channel seismograph. Therefore, the mean magnitude difference was smaller for Bouga's School seismograph measurements $(0.26)$ than that of Kyparissia's School (0.43) (Table 1).

The difference was attributed to increased noise in the records, due to large epicentral distance, which resulted in erroneous picking of $\mathrm{P}, \mathrm{S}$ and coda times. This is also the reason why teachers and students measured different magnitudes on the same graph (Table 2).

Table 2.

\begin{tabular}{|c|c|c|c|c|c|}
\hline \multicolumn{5}{|c|}{ Magnitude estimations of Kyparissia's School (earthquakes from the region of Megalopoli) } \\
\hline DATE & HOUR & $\begin{array}{c}\text { DISTANCE from } \\
\text { Kyparissia's sta- } \\
\text { tion }\end{array}$ & $\begin{array}{c}\text { MAGNITUDE1 } \\
\text { student }\end{array}$ & $\begin{array}{c}\text { MAGNITUDE2 } \\
\text { teacher }\end{array}$ & $\begin{array}{c}\text { EMSC's } \\
\text { MAG }\end{array}$ \\
\hline $6 / 8 / 2009$ & $02: 49$ & $22 \mathrm{~km}$ & 2,34 & 2,55 & 3,3 \\
\hline $6 / 8 / 2009$ & $04: 58$ & $50 \mathrm{~km}$ & 3,61 & 3,89 & 4,6 \\
\hline $6 / 8 / 2009$ & $05: 42$ & $27 \mathrm{~km}$ & 2,47 & 2,61 & 3,1 \\
\hline
\end{tabular}

This is probably the major problem in estimating the earthquake's magnitude correctly. Students' estimations are better when they define the endpoint of an earthquake as the point where all perturbations on the graph have ceased. The problem becomes larger if there is also "noise" coming from school activities that take place close to the sensor. It's almost impossible in these cases (especially for the schools using one coordinate sensors) to estimate properly the duration of an earthquake.

In any case, the difference in magnitude from EMSC or other scientific institutes' data is completely acceptable for the educational purposes. The difference can be minimized through a calibration procedure. The seismograph provides a very useful educational tool and a three coordinate sensor gives better data as it helps students to define more accurately the $\mathrm{S}$ wave picks and the duration of an earthquake. 


\subsection{Advances from the use of educational seismograph}

The use of the educational seismograph improve scientific literacy, spark student interest in scientific research, increase their understanding of natural hazards, and to actively engage them in real-world scientific research. Up to now the use of the tool, in the framework of network "Egelados", not only connects the participating schools but also gives the opportunity for further collaboration among teachers and students that have installed a similar instrument. More specifically the use of the educational seismograph, promotes:

a) Experimental science in schools: The measurements and follow-up of Earthquakes request to students to develop scientific knowledge, dexterities and skills in experimental science (measure, observe, gather and organize data, test hypothesis, present results and draw conclusions).

b) New technologies use: the implementations of seismic data from the schools' seismograph demand data processing and a special software use, so that students can have a visual representation of the seismic activity of their region. This procedure requests to students to develop new technology skills.

As well as, educational seismograph use supports:

c) Inter disciplinary approach: The recording of the seismic activity through the educational seismograph is a complex procedure. Students need to implement knowledge from different disciplines like geology, physics, mathematics, as well as other disciplines like arts, history and languages. A specific curriculum unit is designed by the steering committee which addresses the national curriculum (YPEPTH 2003a; YPEPTH 2003b) in geology, physics, mathematics, geography, environmental education etc. and offers opportunities to involve students in interdisciplinary approaches.

d) Team work and collaboration: Collaboration nowadays seems to be a major task in education. Students need to collaborate and to work in teams in order to interpret scientific data and draw conclusions, as well as, they have to work with other schools (minimum three) in order to specify Earthquakes epicenter.

\section{Conclusions}

The use of the educational seismograph within the frame of geosciences subjects or environmental education projects creates new opportunities for students and teachers to gain knowledge and apply teaching methods appropriate also for the interdisciplinary curriculum. Students have opportunities through the seismograph to explore an earthquake at the time it occurs collecting data from scientific institutes and universities and processing them with their schoolmates from other schools.

Evaluation of the seismograph and data processing gives them opportunities to get used to scientific methods. Student estimations produced from the processing of the seismograph's data showed declinations of $0,25-0,35 \mathrm{M}$.

More modules for students are necessary for project completeness while network continuity and evolution demands even more cooperation between network's steering committee, research institutions and universities. The network is still working on a volunteer basis however financing of the network is necessary in order to attract schools that could participate in it, using their own seismographs. Achieving a long life for such projects requires, besides pedagogical and scientific support of the network's steering committee and ethical support from the educational authorities, financing and a periodical revision of the teaching modules so that schools continue to be interested in participating to the network.

In the school environment, the study of earthquake phenomenon demands knowledge from various disciplines like geology, physics, mathematics, history, geography and technology. As such, it can be 
a successful example of a model, based on techniques that interdisciplinary approach uses. However, such an approach requires knowledge and instruments that schools of secondary education don't usually have and of course lack of knowledge and instruments discourages teachers and students from participate in such initiatives.

A system of students and even teachers evaluation participating in the project through certification and a program for post-graduate studies (for example a Master degree on Geodidactics) for teachers working on such projects could help motivate students and teachers who get involved. Publication of student work in local newspapers and magazines could help as a public acknowledgment of their work, encouraging them to keep working in spite of the difficulties in finding time and study conditions that they might face working on such a project.

Finally teachers' persistence in applying new teaching methods trying to infuse in their students the spirit of research and excite their interest in science is a major factor in networks continuity and success.

\section{Acknowledgments}

Authors would like to thank students and teachers who participated in Egelados network.

\section{References}

Berenguer, J.L., and Virieux J., 2006. Projet éducatif “Sismo des Écoles”. Geósciences, BRGM'S journal for a sustainable Earth, 4.

Bobbio, A., and Zollo, A., 2000. The educational broadband seismic network at Naples (Southern Italy), Orfeus, Electronic Newsletter, 2(3), 23.

EDUSEIS-The Educational Seismological Project. URL:http://eduseis.na.infn.it/sitoing/ project/goals.htm

Egelados-School Educational Seismological network. URL:http://egelados.sch.gr

Federenko, Y.V., Husebye, E. S., and Boulaenko, E., 2000. School yard seismology. Orfeus, Newsletter, 2(3), 22.

Fermeli, G., Alexandropoulou, S., Sokos, E., Foundas, P., and Germenis, N., 2006: Earthquakes and school community - thematic network Egelados _ ID 1916. First European Conference on Earthquake Engineering and Seismology. 3-8 September 2006, Geneva, Switzerland.

Foundas, P., and Germenis, N., 2007. “Educational Seismograph”, User manual, Patras, Industrial Systems Institute and University of Patras, Seismology Laboratory, 33pp.

Husebye, E.S., Beketova, E., \& Fedorenko, Y.V., 2003. School yard seismology, Journal of Geoscience Education, 51(3), 329-335.

IRIS-Incorporated Research Institutions for Seismology. URL: http://www.iris.edu/hq

PEPP-Indiana University program. URL: http://www.indiana.edu/ pepp/indianapepp.html

S.S.N-Seismological Society of America-Education. URL:http://www.seismosoc.org/society/ education/

S.S.N-Seismological Society of America-Seismological Research letters. URL:http://www. seismosoc.org/publications/srl/eduquakes.php

USESN, 2001. Shaking up America's Classrooms: A Vision for Educational Seismology in the United States. Available online at: http://www.indiana.edu/ usesn/text/eos.html

Virieux, J., 1999. EDUSEIS, An EDUcational SEISmological European Network, Orfeus, Newsletter, 1(2), 13.

YPEPTH-Ministry of National Education and Religious Affairs, 2003a. Curriculum for compulsory education, Athens, Governmental newspaper, 303(B-13/3/03), 3733-4416.

YPEPTH-Ministry of National Education and Religious Affairs, 2003b. Curriculum for compulsory education, Athens, Governmental newspaper, 304(B-13/3/03), 4069-4416. 